\title{
On Computer English New Words' Cognitive Semantics
}

\author{
Cao Min
}

Linyi University, Yishui, Shandong, 276400

\begin{abstract}
Keywords: Language cognitive science; Cognitive mechanism; Computer new word; Conceptual integration
\end{abstract}

\begin{abstract}
The generation of new words has special era and social background. Since the 1980s, computer technology has obtained rapid development and popular vocabulary appears with the computer development and gets fast popularization. This paper, combined with practical work, analyzes this kind of computer English new words from the perspective of language cognitive science, and explores cognitive mechanism of new meanings words and new formation words.

With the development of computer technology, human rapidly gets into the information age. In the information age, many new things have spawned, and its progress and development also affect the human way of life. In such an era of rapid development, language is undoubtedly an important medium of information acquisition and transmission, and in the rapid developing information era, not only a lot of computer new words generate, but many existing words are endowed with new meanings. Their ideographic function also changed under different scenes and events. How do new words generate? What kind of changes has taken place in cognitive semantics? These provide a new direction for computer new words linguistics study.
\end{abstract}

\section{THE UNDERSTANDING PERSPECTIVE OF THE NEW WORDS}

For the definition of new words, there is no common understanding in current academia. Due to the different formation of the new words, a lot of different factors make various understanding of new words. If from the perspective of time, new words are the vocabulary appeared in the new period; from the perspective of compiling dictionaries, new words are those that are not authoritative dictionary words; from the perspective of stability of new words meaning, they are more unstable semantic vocabulary; from the angle of psychology, the speaker gives new context and meaning to the new words. In short, new words understanding are different with different angle, and have different concepts. But no matter what angle and cognitive, new words are "new". The rapid development of computer technology produces a lot of new things. People can't use existing vocabulary to explain these new things. There are barriers existing in communication and through the combination of words, assign meaning, and create new words. From the perspective of language cognitive science, new words can be divided into two ways: one is to create new words combining with new things; one is the expansion of original semantic category. In reality, these two approaches are not mutually independent. Most of the time, they are a combination, and are realized on the basis of conceptualization and categorization of the real world. Through the existing concept prototype of vocabulary, create new words and meanings so as to reduce the burden of memory and cognitive difficulty and improve the flexibility and adaptability of information transmission.

\section{COMPUTER ENGLISH NEW WORDS' COGNITIVE MECHANISM}

With the development of language cognitive science, linguists find that the generation of new words is not random, but has certain development and creation reasons. Its production process can be taken as a cognitive process, rather than imagined. People often get a new word through the existing data and information by using the basic word formation method. From a lot of new words, this feature can be seen. This paper explains the cognitive mechanism of computer English new words combined with concept integration and metaphor in cognitive linguistics. 


\section{A. Cognitive motivations}

The so-called cognitive motivations have no clear definition. It is directly defined as "non-arbitrariness" at present. Hiruga in 1994 understood motivations as that relation between meaning and form of language is arbitrary. Lakoff (1987) argued that language motivation was "Interpret ability". Although different, cognitive motivations have special performances: (1) special morphological, such as compound has very high motivations. For instance: "hear" is the combination of result and work; (2) semantics has conceptual metonymy; (3) syntax level, which is sentence structure, is reasonable, such as structure has all kinds of iconicity. A word's semantic is shown by constant changing meaning. In addition to the basic meaning, there are other additional meaning and concept meaning, and new words appear by integrating the concept of metaphor and combination, and new word semantic understanding can help us better master, understand and apply.

\section{B. Metaphor motivations}

Cognition is a response to the reality, and language outlines and summarizes the cognitive process in thinking and records it. The naming of something new is the basic function of the new words, and when to name new things; metaphor reflects its associated value and creative value to new things. In describing new things, people tend to contact their perception of life and life experience and select consistent and known things to describe them. For example, surf for online applies a similar action and behavior to describe a new computer thing. The properties and actions migration and borrow are word metaphor process. There are a lot of screening, comparison and association in this process. First, filter the comparable things, then make a lot of comparison of similar words, finally after association, relate the correct word. And after a series of screening, comparison, association, words usually have a lot to do with the real things, so words are easy to accept and recognize. Plenty of computer English new words have showed the characteristics of metaphor, such as operating system is identified as Windows; the operating systems are compared to many different "windows"; a computer table is identified as "desktop"; the desktop wallpaper uses "wallpaper". There's more, such as electronic mail as E-mail, click on the home page as "click," "firewall", system vulnerabilities "bug", more CPU load as "load" and so on.

\section{Metonymy motivations}

Like metaphor, metonymy is one of the most important psychological mechanisms for people's concept formation. Metonymy often occurs in the same idealized model, and transforms from one entity to another entity concept. The former is swivel, while the latter is metonymy goal. Its essence is to get near the concept layer, which is near sexual psychological foundation. One concept tends to have more understandings. Humans tend to select several important features to generalize these understandings. Sometimes, classify several important features, so some are important and others are secondary. When new words are created, people tend to focus on performance and highlight one or several important characteristics of new things, use language symbol to represent new things, and this process is metonymy. Computer English new words' structure are most in accord with the idea of metonymy, such as pen pal and key pal are respectively pentizens and netizens. People use keyboard instead of a pen to communicate. Keyboard naturally is transferred as one of the most important parts in computer. Face time is used to denote the communication time of meeting friends online.

\section{Analogy motivations}

Analogy is one of the cognitive mechanisms of new words. In the face of new things, people seek similarity from the objective world and consistency things. The analogy and similarity between is considered adjacent effects of cognitive world. Analogy's basic method is to compare the existing words, analogize, associate and create similar words, and use the existing practice of language itself, according to the paradigmatic relations, create new things and concepts and relationships through morpheme words. Information technology not only brings people convenience, for example, at the same time it also brings a lot of trouble and pressure. People move the anger to information and technology so there was a group of similar words such as "e-rage", "IT rage", "the tech rage" and "PC rage", etc. 


\section{E. Conceptual integration}

Conceptual integration is also people's kind of creative thinking process. Conceptual integration theory was first founded by Fauconnier and Turner and was the important part of cognitive linguistics. The integration is not something attached to this world, but is a kind of tool we use to live in this world. Concept integration divides human mental space into four, respectively are: a synthesis space, a generic space, and two input spaces. Four spaces make corresponding connections through space projection. Two input spaces project onto a generic space by a total structure and information, and also can project on synthesis space. People's creation and use of new words are instantaneous, such as social bookmarks. Bookmark is originally paper bookmark, but social bookmarks are Internet users' collection of the interested web pages and then in the sharing. Based on conceptual integration theory, analyze input spaces respectively as "web page" and "print page". Through generic space projection, both input spaces can be read, sign and collection, etc., and get new words social bookmark by synthetic.

\section{THE FORMATION AND CHARACTERISTICS OF COMPUTER ENGLISH NEW WORDS}

\section{A. Base class new words}

Base class vocabulary is mostly created. A large number of computer English new words belong to it, and common base class vocabulary is $\mathrm{WiKi}$, Chinese translation Weiji. The source is a word in Hawaiian language we kee wee kee, namely to hurry up. Blog is short for weblog, which comes into being based on web logs and can use more ways to show their life experience. Grid is one network.

B. New words with numbers and simplifications

Using numbers' harmonics in simplified writing is also an important way for computer word formation, of which 2 and "two", "to" application is more common. P2P, for example, is Peer-to-peer, namely point to point or end to end, and P2P is used to denote node to node. Similar to it, there are B2B, info4Java (4 harmonics for), B2B, B2C, etc.

\section{Specific vocabulary}

Some common vocabulary gives a new meaning or metonymy, and such words also can't use the traditional thinking to understand. Commonly, there is Bluetooth. The original intention is the nickname of Danish king because he loved to eat blueberries and his teeth were dyed blue. The metaphor explains that infinite transmission technology of short distance is like a Bluetooth to navigate in the Internet world. Similarly there is Finger. Originally it referred as hand fingers but now it means the registered account information, and Archive, Gopher, Quantum, etc. are other examples.

D. Acronym new words

Another characteristic of computer English new words is acronym, generally the beginning and the end of the word letter to form new words. Acronym can save a lot of writing and input space and is a common method of word formation in computer age. There are XML, WSDL, FTP, PKI, UDDI, MRO II, ERP, NFC, etc.

\section{CONCLUSION}

Language is not only a tool of communication, but a mirror of social development. A lot of new words show the rapid development of society, economy, science and technology. The cognitive semantics of new words meet people's cognitive thinking and psychological characteristics. This paper analyses computer English new words based on cognitive linguistics, explains the cognitive mechanism of new words, and provides reference for the cognitive semantic research of computer English new words.

\section{REFERENCES}

[1] Cao Tian. 2004-2013 Computer class English new words' cognitive motivations analysis [J]. Journal of Changchun College of Engineering (Social Science Edition), 2014 01:60-63. 
[2] Si Aixia, Zhang Qianghua. The composition characteristics and translation of computer English new words [J]. Journal of Weifang College of Education, 2011, 12:95-96.

[3] Yang Ying, Guo Caiyun. Technology characteristics and translation of English new words [J]. Journal of Shaanxi University of Science and Technology (Natural Science Edition), 2009, $11: 177-181$.

[4] Lin Jiejun. Network new words coined words way study based on corpus investigation and language contrast [D]. East China Normal University, 2005.

[5] Si Aixia, Zhang Qianghua. Computer English new word spyware interpretation [J]. Journal of Lishui Institute, 2008, 11:61-62.

[6] Han Qingguo. English new words and their Chinese translation studies [J]. Journal of PLA Foreign Languages Institute, 2003 practices: 9-13.

[7] Liu Yan, Wang Dou'e. Network English new words production and development [J]. Journal of Mudanjiang University, 2010, 2010:52-54.

[8] Chang Wenmei. Structure and characteristics of network English new words [J]. Journal of Yancheng Normal University (Humanities and Social Science Edition), 2013, 11:78-80. 